\section{On the rocks}

\section{J. Oerlemans}

The Growth and Decay of Ice. By G. S. H. Lock. Cambridge University Press: 1990. Pp.434. £65, $\$ 100$.

WrITING a treatise on the appearance of ice on Earth on all possible space scales, from the molecular to continent-sized ice sheets, is truly ambitious. From a general scientific point of view, I can appreciate the charm of placing our knowledge of ice in a single framework, naturally built around the basic physical principles involved.

When reading The Growth and Decay of Ice, my initial enthusiasm turned into doubt. In which sense, for instance, can freezing in an ice-resistant insect be related to the effect of solar insolation variations on ice sheets? This book actually shows that parallels in conceptual development of methodology between the study of ice on the molecular/microscale and the study of its role in the large-scale geophysical environment are hard to find. Frozen water is the binding element, but that is all.

After a general introduction, two chapters are devoted to a thorough treatment of the thermodynamics of ice. This treatment is formal and rigorous, and of considerable didactic quality. Then chapters follow on ice and water', 'ice and air', 'ice and Earth', 'ice and life' and, finally, 'decay of ice'. It is not surprising that these topics fill over 400 pages. With respect to 'ice and water', an interesting discussion is provided on the effect of convection (free and forced) on planar growth, and a short but instructive view is given on freezing on submerged bodies. In 'ice and air' the discussion

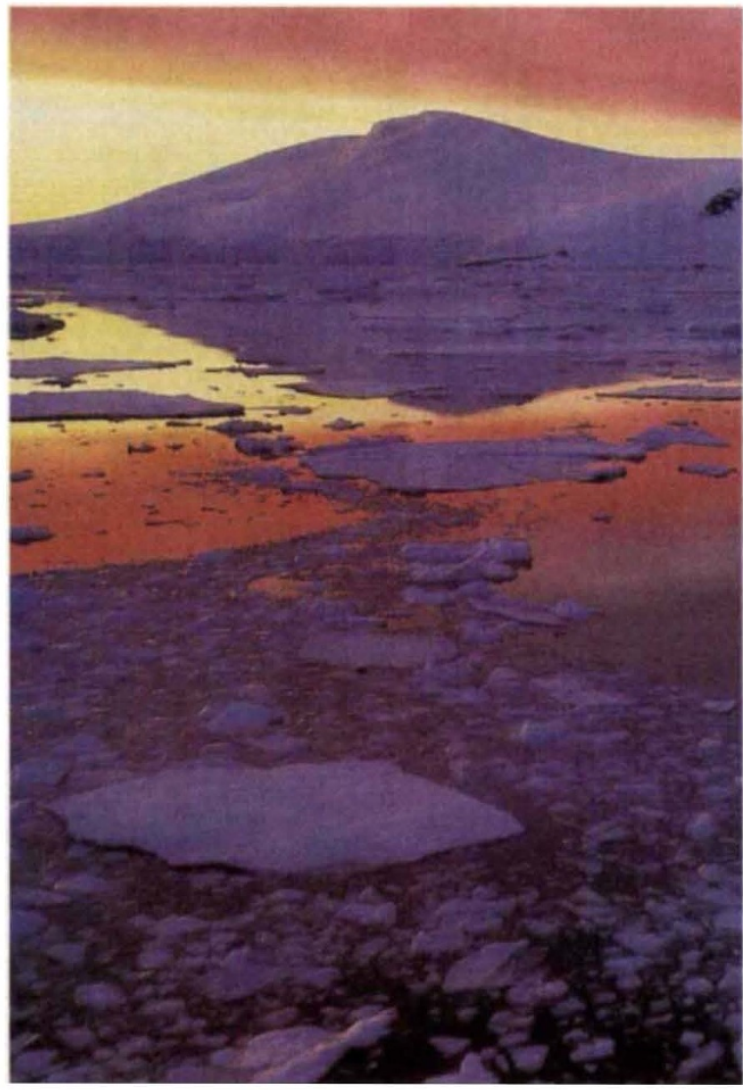

Sunset on ice - the Lemaire Channel in the Antarctic (taken from Wild Ice, by R. Naveen, C. Monteath, T. De Roy and M. Jones (Smithsonian Institution, 1990, \$29.95)). centres around the formation of cloud droplets and ice crystals, riming and icing on offshore and land-based structures. Surface energy exchange is the starting point in the chapter on 'ice and Earth', followed by sections on the pores system, with reference to the surface morphology of glaciers, and on permafrost. In 'ice and life', topics of study are freezing in biofluids, small organisms, plants, animals and, partly as an interesting application, foods. The final chapter on the 'decay of ice' is surprisingly short.

Throughout the book, the treatment loses considerable depth when larger-scale features are considered in the global context. Many statements on glaciations, ice ages, climate sensitivity, large-scale snow cover

and sea ice are superficial and based on old material (for instance, a single sentence stating that S. H. Schneider and T. Gal-Chen have calculated (in 1973) that a two per cent drop in the solar constant would lead to a global temperature below $0{ }^{\circ} \mathrm{C}$, without further discussion). For a text of this type, the number of listed papers from the past decade is remarkably small. This cursory treatment is not justified; in the past $10-20$ years, a tremendous amount of work has been done on such topics. Furthermore, the possibilities offered by satellites and powerful computers are hardly mentioned.

In making a personal judgement, it appears natural to split the material in this book into two parts. The first is on the

\section{a}

